\title{
The Case That Alternative Argumentation Drives the Growth of Knowledge-Some Preliminary Evidence
}

\author{
CONNIE MISSIMER Seattle, Washington
}

Key Words: alternative argumentation, evidence, external support, intuitive fallacy, reasonableness.

Abstract: Argumentation theorists can make a much larger case for the significance of their discipline than they appear to do. This larger case entails asking the overarching question, "How is knowledge driven?" and seeking the answer in arguments for which there is near universal agreement that they drove the growth of knowledge. Three such benchmark arguments are Newton's on motion, Darwin's on evolution, and Mill's on women's intellectual equality to men.

These and other seminal historical arguments suggest that alternative argumentation in light of evidence is the mechanism which drives the growth of knowledge. There are also a number of surprising results, among them that even the most epistemically salient arguments contain significant errors and that what is "reasonable" is a constantly changing intuition which is biased against superior but novel ideas. This approach suggests a new fallacy as well, the intuitive fallacy of believing that plausibility is evidence for likelihood.

\section{Introduction}

In over more than twenty centuries, the study of argumentation has developed a rich assortment of theories. I like to imagine someone coming upon all these theories for the first time. How might she decide which of them to believe? She might look for claims which many or most hold in common, for example the dialogical requirement of argumentation. Or she might ignore majority opinion and decide on a theory, or aspects of several theories, which most closely fit her intuitions.

Both strategies are sensible. But are they enough? Might she wonder, if only late in the night, whether her intuitions and/or the authorities are right? This is the epistemic worry of which Perelman would want to relieve us by claiming that the purpose of argument-and by extension, argumentation-is to produce assent rather than demonstrate truth.' Evidence in this paper suggests that Perelman has got this point the wrong way around. Demonstrating something to be more likely true than its alternative will be more likely to produce assent, at least in the long run. If our imaginary woman is a worrier, she would welcome evidence which is external to her deeply-held intuitions and those of argumentation authorities, even if it points against them.

The external evidence presented here is three arguments which are distinguished by the fact that they are epistemically salient to a high degree across disciplines-indeed, our daily experience would be incomprehensible without them. Without Newton's theory of motion we could not travel by airplane; without the theory of evolution we would not have the sense of the connectedness of animals which developed into the study of ecology, nor would we derive the results we have from genetic experimentation on animals as unlikely as fruit flies 
to discover the cures for many human diseases. Without an argument for equality of the sexes, the myriad achievements of women across academic, political and business fields would be incomprehensible. ${ }^{2}$

Of course, these three successful arguments have given rise to problems: airplanes pollute, genetic engineering can be misused, and men, women and children are still struggling with the social ramifications of equality. The problems, however, constitute yet more evidence that in these instances we have acted on a kind of knowledge which has transformed the world, and my imaginary woman could think of them as data points against which she might test the various claims of argumentation theorists. She might reason that if these arguments had certain common features and clearly managed to drive the growth of knowledge, then she couldn't go far wrong in emulating their common components.

Now, Willard has interesting things to say about external support projects, which he terms "borrowing from other fields" for the purposes of "getting epistemologically better." He notes:

It has been common in philosophy's history for particular thinkers to use selected aspects of physical theories in vogue: Kant appropriated Newtonian space and time to create the a prioris of cognition, just as contemporary thinkers wrestled with the Copernican Interpretation. This is interesting because thinkers who hitched their wagons to this or that physical model did so by virtue of arguments that forced them to share the physical model's fate. (Willard, p. 71)

However, the effort here is different. There is no importation of the concepts of motion or evolution or equality into a theory of argumentation. For instance, I am not claiming that an argument is in a state of rest and motion at the same time, or that there are natural selection pressures on arguments. Rather, the strategy is to use the heft or weight of these arguments, skimming their epistemic cream as model arguments from disparate fields to enrich argumentation theory. Since they have demonstrated the necessary and sufficient conditions for the growth of knowledge, a theory of argumentation should capture those features they share.

Willard notes that "fields borrowing from other fields do, as a practical matter, obligate themselves to attend to the arguments of the fields borrowed from. They hold themselves accountable to the outcomes of arguments in the raided fields" (Willard, p. 72). It is difficult to imagine any argument about argumentation which it would be as easy to hold oneself accountable to as these three major underpinnings of physics, biology, and politico-social studies. This does not denigrate the arguments in the field of argumentation nor those who contribute to it, but merely points to the difficulty of our task and the clear opportunity to get epistemically better by the external support of arguments which hold such strong interfield acceptance and whose effects we feel daily.

Now to place each of these three arguments in context and discuss two major features which each shared, namely a sense of unreasonableness to most of their readers and a great supply of external support (evidence). 


\section{Mill on Women}

When John Stuart Mill wrote On the Subjection of Women, a married woman was not a separate legal entity. ${ }^{3}$ If the husband died first she inherited no property nor could she raise her children unless he had willed it. If she left him, he could compel her by law to come back. These laws were considered reasonable, because the general view of women was that men were more intelligent, and that women, although charming, were emotional and fragile. Mill's view was unusual. He argued that the subordination of one sex to the other ought to be replaced by "a principle of perfect equality, admitting no ... privilege on the one side ..." (Mill 1985, p. 219).

Mill goes on to argue that while in fact the burden of evidence lies on the side arguing inequality, he is the one who will have the burden of evidence, and a monstrous one:

It is useless for me to say that those who maintain the doctrine that men have a right to command and women are under an obligation to obey, or that men are fit for government and women unfit, are on the affirmative side of the question, and that they are bound to show positive evidence for the assertion, or submit to [its] rejection .... . [Yet] before I could hope to make any impression, I should be expected not only to answer all that has ever been said by those who take the other side of the question, but to imagine all that could be said by them . . . and besides refuting all arguments for the affirmative, I shall be called upon for invincible positive arguments to prove a negative. And even if I could do all this ... I should be thought to have done little; for a cause supported on the one hand by ... so great a preponderance of popular sentiment, is supposed to have a presumption in its favour, superior to any conviction which an appeal to reason has power to produce in any intellects but those of a high class. (Mill 1985, p. 221)

Mill does not blame his reader for "having too little faith in argument, but for having too much faith in custom and the general feeling" (Mill 1985, p. 221).

How does he attack this almost insupportable weight of the reasonable view of the relations between the sexes? One might expect from a philosopher a philosophical principle abstractly argued. But he does not do this. He brings a surprising amount of historical evidence to this philosophical debate. The work is 96 pages long, and conservatively, 34 pages of it contains historical evidence ranging across Western history from Homer through to current events, with occasional references to the Middle and Far East. ${ }^{4}$

Some of his major evidentiary support is to show that the reasonable nineteenth century view of equality among males was once considered unreasonable. Regarding slavery, he argues that

... no less an intellect, and one which contributed no less to the progress of human thought, than Aristotle, held this opinion without doubt or misgiving; and rested it on the same premises on which the same assertion in regard to the dominion of men over women is usually based, namely that there are different natures among mankind, free natures, and slave natures; that the Greeks were of a free nature, the barbarian races of Thracians and Asiatics of a slave nature. 
But why need I go back to Aristotle? Did not the slave-owners of the Southern United States maintain the same doctrine, with all the fanaticism with which men cling to the theories that justify their passions and legitimate their personal interests? (Mill 1985, p. 229)

After discussing the assumed superiority of lord over serf in the Middle Ages, Mill concludes, "The subjection of women to men being a universal custom, any departure from it quite naturally appears unnatural" (Mill 1985, p. 230).

The Subjection does contain subarguments which we might find silly or offensive today. For instance, Mill argues that although women are more excitable, they can still be the intellectual peers of men. He writes:

The French and the Italians are undoubtedly by nature more nervously excitable than the Teutonic races, and compared at least with the English, they have a much greater habitual and daily emotional life: but have they been less great in science, in public business, in legal and judicial eminence, or in war?"

(Mill 1985, p. 279)

Such examples do not lessen Mill's achievement; however, they do show that even this great argument is not free of elements which some might label poor reasoning, particularly if they didn't know the source.

The reception of Mill's argument was unenthusiastic. Historian Sue Mansfield notes, "For its time, Mill's point of view was extremely avant-garde and relatively isolated." Mill waited eight years before publishing the Subjection, fearing that it was too radical. Though the work enjoyed two English editions and was published abroad, it was also greeted with extreme hostility and attacked as "indecent" and an incitement to "rank moral and social anarchy" (Packe, pp. 494-96). Although he was defeated for reelection to Parliament in 1868, Mill's influence caused the House of Commons to pass the Married Women's Property and National Education acts, which made education mandatory for girls as well as boys. Nine years after the Subjection appeared, parliament granted women the right to separation from husbands convicted of aggravated assault on them, and custody of children under ten years old (Packe, $\mathrm{pp}, 494-96)$. Still, it would take another fifty years of intense argumentative struggle in England before the full enfranchisement of women occurred. The story in the United States is similar.

\section{Newton on Motion}

Two hundred years earlier, Isaac Newton faced a similarly formidable argumentative task. In the seventeenth century the dominant view about moving objects seemed as reasonable and obvious as inequality between the sexes. That view was the intuitive sense that within a moving object there is an impetus which is given from an outside force. Historian Herbert Butterfield describes how today we discount the difficulty in overcoming such a reasonable view:

... things which we find it easy to instil into boys at school-things which would strike us as the ordinary natural way of looking at the universe, the 
obvious way of regarding the behavior of falling bodies, for exampledefeated the greatest intellects for centuries, defeated Leonardo da Vinci and at the marginal point even Galileo, when their minds were wrestling on the very frontiers of human thought with these very problems. (Butterfield, p. 14).

Newton confounded the reasonable perception by positing a state of rest and a state of uniform velocity as equivalent, while observation makes an intuitive distinction between a state of rest and a state of motion.

Besides our intuitive perceptions, two great argumentative stumbling blocks to the Newtonian view were the Aristotelian view and the continuation of two of its core assumptions by Descartes. The Aristotelian view was itself a stupendous intellectual feat and made alternative theories that much harder to generate (Butterfield, p. 14). The Aristotelian theory held that all heavy terrestrial bodies had a natural motion towards the centre of the earth. But motion in any other direction, such as that caused by two people tossing a ball back and forth, was violent motion, contradicting the ordinary tendency of a body (here, a ball) to move to what was regarded as its natural place, down to the ground. Such motion of the ball depended on the mover. It was motion, not rest, that always required to be explained.

Further, Aristotle held that a vacuum is impossible and that objects could only influence one another if they actually touched-there could be no such thing as action at a distance. Descartes, despite his efforts to jettison all past prejudices, imported these two principles into his view that every fraction of space should be fully occupied all the time by continuous matter, particles packed so tightly that one of them could not move without communicating the commotion to the rest. This matter formed whirlpools in the skies, each planet caught in its own whirlpool and carried around its orbit like a piece of straw (Butterfield, pp. 15960).

Newton's essential feat was the demonstration that when his new conception of terrestrial mechanics was applied to the heavenly bodies the mathematics came out correctly. Newton seems to have achieved this synthesis in $1665-66$, although he was dissatisfied with certain points in the demonstrations and apprehensive about the reception of his radical ideas. He put the work away for twenty years (Butterfield, p. 165). The Principia was finished in 1686.

Unlike Mill, Newton did not preface his thesis with arguments about the great difficulty he faced of convincing theoretical rivals like Descartes. Yet Butterfield notes the reaction to the work:

Even mathematicians did not immediately grasp the meaning and the importance of the Principia, and many people-especially those who were under the influence of Descartes -regarded Newton as unscientific in that he brought back on to the stage two things which had been driven out as superstitious namely, the idea of a vacuum and the idea of an influence which could operate across space between bodies that did not touch one another. His "attraction" was sometimes regarded as a lapse into the old heresies which had attributed something like occult properties to matter. (Butterfield, p. 169) 
Like Mill's proposal for equality, Newton's system was severely criticized. Newton himself declared his theory "absurd," not only because it equated rest and uniform velocity but because it implied a concept of gravitational attraction which seemed spiritualist and a throwback to a discredited argument of Aristotle that the falling body moved more jubilantly every moment because it found itself nearer home (Butterfield, p. 18). In his "An Essay On the Causes of the Heavenly Motions," Leibniz set out a complex alternative, which throughout his life he considered as great as the Principia, and far preferable from a philosophical point of view. This theory contains what now seems quite peculiar talk of conspiring motions and a harmonic vortex of matter that bore planets around. Leibniz tried to find a mechanical explanation for gravity because he found the idea of action at a distance highly unreasonable.

Like Mill's Subjection of Women, Newton's work was imperfect. In Philosophers at War, A. R. Hall chronicles the argumentation surrounding Newtonian mechanics, noting that "for all his profound intuitive grasp of the rightness and good sense of what he was doing, Newton was unable to give complete logical validity to an infinitesimal calculus, leaving cracks into which Berkeley and other critics could insert powerful destructive wedges ..." (Hall, p. 32). And even in the Principia, Newton provided an unsound demonstration of the correct result that the moment of any quantity $x^{n}$ is proportional to $n x^{n-1}$. This is a central error; the correct version of that formula is the beginning of the calculus that everyone learns (Hall, p. 32).

Argumentation over motion would continue for another hundred and forty years, with the English generally supporting Newton, the French tending towards Descartes. Butterfield notes that ". . . the ultimate victory of Newton . . . vindicated the alliance of geometry with the experimental method against the elaborate deductive system of Descartes" (Butterfield, p. 170).

\section{Darwin on Evolution}

Like the works of Mill and Newton, Darwin's Origin of Species is heavily laden with external support, his myriad observations of species from disparate parts of the world and those of other naturalists. You can open the book at random and find this support on virtually every page, for example, a discussion of the optic nerve of articulata, features of long-toed concrakes, auks, or the reappearance of minute dangling horns in hornless breeds of cattle. At around 420 pages the book is four times as long as the Subjection, far smaller than the work which Darwin had intended, but he felt compelled to publish because Wallace had come to the same general conclusions Darwin had as a result of his studies of the Malay archipelago. Nervous about the reception of his views, like Newton, Darwin held back for twenty years.

Darwin opens The Origin with the commonly-held alternative to his position, which we have all but forgotten: 
Until recently the great majority of naturalists believed that species were immutable productions, and had been separately created. This view has been ably maintained by many authors. Some few naturalists, on the other hand, have believed that species undergo modification and that the existing forms of life are the descendants by true generation of pre-existing forms. (Darwin 1958, p. 1)

Darwin characterizes his book as "one long argument" (Darwin 1958, p. 394). Unlike Mill, who took his reader back in history, Darwin pries the reader loose of her prejudices by beginning at home, his first chapter pointing to the variation among domestic animals. He says that "No case is on record of a variable organism ceasing to vary under cultivation. Our oldest cultivated plants, such as wheat, still yield new varieties: our oldest domesticated animals are still capable of rapid improvement or modification" (Darwin 1958, p. 14).

It is clear that Darwin is writing against the reasonable tide. In a telling passage in which he explains how evolution can account for the development of even as exquisitely sophisticated organ as the human eye, he writes:

To suppose that the eye with all its inimitable contrivances for adjusting the focus to different distances, for admitting different amounts of light, and for the correction of spherical and chromatic aberration, could have been formed by natural selection, seems, 1 freely confess, absurd in the highest degree. When it was first said that the sun stood still and the world turned round, the common sense of mankind declared the doctrine false; but the old saying of Vox populi, vox Dei, as every philosopher knows, cannot be trusted in science. Reason tells me, that if numerous gradations from a simple and imperfect eye to one complex and perfect can be shown to exist, each grade being useful to its possessor, as is certainly the case; if further, the eye never varies and the variations be inherited, as is likewise certainly the case; and if such variations should be useful to any animal under changing conditions of life, then the difficulty of believing that a perfect and complex eye could be formed by natural selection, though insuperable by our imagination, should not be considered as subversive of the theory. (Darwin 1958, p. 146)

Darwin offers prodigious amounts of evidence that his opponents are wrong, discussing the giraffe, Niata cattle in South America, racehorses, Greenland whales, insects, and petrels (Darwin 1958, pp. 177-184). The various objections to evolution seems as bizarre today as preoccupations with women's mental weakness or Cartesian whirlpools. For example, Darwin writes:

We are ... brought to the question which has been largely discussed by naturalists, namely, whether species have been created at one or more points of the earth's surface. Undoubtedly there are many cases of extreme difficulty in understanding how the same species could possible have migrated from one point to the several distant and isolated points, where now found. Nevertheless the simplicity of the view that each species was first produced within a single region captivates the mind. He who rejects it, rejects the vera causa of ordinary generation with subsequent migration, and calls in the agency of a miracle." (Darwin 1958, p. 314)

Darwin was up against the discipline of geology as well, having to argue that the absence of fossil records of all this evolution was due to the fact that 
geological estimates of the age of the earth were seriously low, and that there were far more fossils than people had yet found. And no less an authority than the leading physicist at the time, Sir William Thomson (later Lord Kelvin), cast serious doubt on the plausibility of evolution by calculating that the earth, as a cooling body could not, on the principles of thermodynamics, have supported life for the many millions of years that the theory required. "It is quite certain that a great mistake has been made-that British popular geology ... is in direct opposition to the principles of Natural philosophy" (cf. in Burkhardt, p. 45).

Despite the brilliance of Darwin's argument, he was wrong about inheritance and the origin of variation, confused about varieties and species, and unable to elucidate the problem of the multiplication of species. ${ }^{6}$

\section{'Reasonableness' and Alternative Argumentation}

In sum, these arguments of Darwin, Newton, and Mill set sail against views which were thought eminently reasonable, armed with views which were received as highly unreasonable, unscientific even, by eminences such as Descartes, Leibniz, and Kelvin. This historical state of affairs poses interesting problems for argumentation theorists who would specify criteria in advance for reasonableness, since these seminal works are evidence that reasonableness is a constantly changing intuition which is biased against superior but novel ideas.

Of course, reasonableness is also biased against inferior new ideas, arguably far more numerous than superior new ideas, and so reasonableness would appear to play a maintenance role in the growth of knowledge. For example, the impetus theory of motion was an improvement on the rather animistic Aristotelian notion that an object fell to earth more rapidly the more joyous it was at reaching its destination; so it was reasonable for people to resist Newton's theory of motion as an apparent throwback to an inferior idea. It would not serve our epistemic interests for everyone to hive off after every new and interesting notion. But it does seem to be a necessary condition that some 'unreasonable persons' should chart a strange course, and then that a number of other 'fools' should rush in, hoping to gather more external support; if the external support continues to build, as it did for the arguments of Mill, Newton and Darwin, then an increasing number people will come over to that view as the evidence mounts in its favour. This is a population view of argumentation, then, that alternative argument by large numbers of people and mounting evidence drive the growth of knowledge and its increasing acceptance. Such a population view does not in any way denigrate the importance of individuals. On the contrary, it shows that without the efforts of countless others, we would not have the sophisticated knowledge that these three theories have become.?

Besides seeming unreasonable these three epistemically salient arguments share a virtual absence of two means of argumentation. There is very little moral support in the form of appeal to like-minded authorities; and there is no intuitive 
appeal at all, perhaps because these views were intuitively unattractive to their audiences.

I have used the unusual term "external support" instead of "evidence," because the latter term has been distorted in philosophical thinking in ways which other fields would find unsatisfactory. A precis of this distortion can be found in the Blackwell Companion to Epistemology, where one reads the following entry under evidence:

The concept of evidence appealed to in evidentialism, and in epistemology generally, differs from the related concept of evidence used in the law. In the law ... evidence includes physical objects and events. ... In philosophical discussions, evidence is generally taken to be either internal states such as beliefs, or the believed propositions themselves. Thus, the belief (or proposition) that a weapon of certain type was used might be evidence for one person's guilt. (Dancy and Sosa, p. 120)

Mill or Darwin would never have successfully argued their unreasonableseeming views without physical objects and events, and no one would ever have come to believe these unreasonable, counterintuitive arguments without external support. Of course, physical objects or events have to be believed in, the inferences from them believed. But it is arguments about new physical objects or events, or casting events in a new and unreasonable-seeming light, which often drives changes in belief:

Some philosophers have claimed that evidentiary support from physical objects and events is a fallacy, the Naturalistic Fallacy of moving from is to ought. How one could choose among conflicting oughts without appeal to physical objects and events is unclear. Certainly the power of Mill's argument was its naturalistic evidence, "the experience of a thousand years" of coming to equality among men. Had Mill not argued with the help of this evidence, he would have remained the easy prey of the well-argued intuitions of the then-reasonable view of women. And the same could be said of Newton and Darwin's arguments. Given this evidence, I would like to suggest a new fallacy, the Intuitive Fallacy, which occurs whenever anyone argues: It is my (well-argued) intuitive belief that $\mathrm{X}$ is or should be the case, therefore $\mathrm{X}$ is or should be the case. ${ }^{9}$ In introducing this fallacy I take moral support from Willard's remark: ". . . I intuit that intuition is nothing but the regnant constructs on cognitive systems..." (Willard, p. 64).

This paper has suggested that alternative argumentation in light of evidence has driven the growth of knowledge. Concrete bench marks of such growth are Newton's argument about motion, Darwin's on evolution, and Mill's argument for the intellectual equality of women. This approach has yielded some predictable results, for example, that a dialogical approach by many people over time appears necessary to repair the errors central to even great arguments, and that "reasonableness" is a constantly changing intuition which is biased against superior but novel ideas. This approach opens up a research agenda by which our 
picture of the rules of argumentation as well as of the fallacies may well change in response to such external support.

1 "To reconcile philosophic claims to rationality with the plurality of philosphic systems, we must recognize that the appeal to reason must be identified not as an appeal to a single truth but instead as an appeal for the adherence of an audience, which can be thought of, after the manner of Kant's categorical imperative, as encompassing all reasonable and competent men." (Perelman 1979, pp. 13-14.)

${ }^{2}$ Lest this appeal to common experience seem philosophically gauche, recently philosophers Robert Brandom, Richard Rorty and Jay Rosenberg argued one another down intricate, brilliant Davidsonian, Sellarsian jathways, both in their papers and on into the discussion. Finally it came down to the question whether Rorty's irony went all the way down, whether humanity had acquired anything that could be termed knowledge. Brandom argued that if we could bring Aristotle back to life, we would not show him a cyclotron or offer up the theory of quantum mechanics, but we would give him medicine because, as Brandom put it, "Aristotle has a body." "Author Meets Critics: Robert Brandom, Making It Explicit," at The American Philosophical Association Pacific Division meeting, San Francisco, California, March 31, 1995.

${ }^{3}$ Blackstone's dictum was that "by marriage the very being or legal existence of a woman is suspended." See Mansfield's introduction to Mill 1980 . p. xii.

${ }^{4}$ Mill 1985, pp. 223-234; 237-239; 244, 246-248; 250; 259-263; 266; 270-273; 279; 285-289; $294 ; 297 ; 300-302 ; 308 ; 316$.

${ }^{5}$ Mansfield in Mill 1980. p. xii.

${ }^{6}$ Ernest Mayr, introduction to Darwin 1964. p. viii.

${ }^{7}$ For further discussion of this population view and the Alternative Argument Theory (AAT), cf. Missimer 1994 and 1995.

${ }^{8}$ It is surprising how seldom in history a person has come up with an epistemically salient idea which was immediately greeted with universal approval and a sense of "How reasonable: Why didn't I think of that sooner?" I cannot think of one major example. The theories of continental drift, or meteoric impact, even of philosophies like that of Karl Popper, are met with a cold shoulder or derision. Cf. Chinn and Brewer 1993 for a large number of historical examples from science.

${ }^{9}$ For an account of the way in which intuitively attractive claims about critical thinking prove inapplicable to historical figures generally considered as great critical thinkers, cf. Missimer 1990 and 1995.

\section{Bibliography}

Achinstein, Peter, editor (1983). The Concept of Evidence. London: Oxford University Press.

Burkhardt, F. (1972). "England \& Scotland: Learned Societies," in The Comparative Reception of Darwinism, Thomas F. Glick, ed. Austin, TX: University of Texas Press.

Butterfield, Herbert (1957). The Origins of Modern Science: 1300-1800. New York: Free Press.

Chinn, Clark A., and William F. Brewer (1993). "The role of anomalous data in knowledge acquisition: A theoretical framework and implications for science instruction," Review of Educational Research 63; 1-49.

Dancy, Jonathan, and Ernest Sosa (1992). A Companion to Epistemology. London: Basil Blackwell. 
Darwin, Charles (1958). The Origin of Species: By Means of Natural Selection or the Preservation of Favoured Races in the Struggle for Life. New York: The New American Library*

(1964). The Origin of Species, Emest Mayr, editor. Cambridge, MA: Harvard University Press.

Hall, A. R. (1980). Philosophers at War. London: Cambridge University Press.

Mill, John Stuart. (1980). On the Subjection of Women, edited by Sue Mansfield. Arlington Heights, IL: Croft's Classics.

(1985). On the Subjection of Women. London: Everyman's Library. Introduction by Mary Warnock.

Missimer, Connie (1990). "Perhaps by skill alone," Informal Logic 12: 145-153.

(1994). "Why two heads are better than one: Philosophical and pedagogical implications of a social view of thinking," in Kerry Walters, ed., Re-Thinking Reason: New Perspectives in Critical Thinking. New York: State University of New York Press. pp. 199. 34. 1-19.

(1995). "Where's the evidence?" Inquiry: Critical Thinking Across the Disciplines 14:

Perelman, Chaim (1979). The New Rhetoric and the Humanities: Essays on Rhetoric and its Applications, William Klubak, trans. Dordrecht / Boston: Reidel.

Packe, Michael St. John (1954). The Life of John Stuart Mill. Old Tappan, NJ: Macmillan.

Willard, Charles A. (1982). "Argument Fields,": in J. Robert Cox and Charles A. Willard, Advances in Argumentation Theory and Research. Carbondale: Southern Illinois University Press.

CONNIE MISSIMER 4836 NE $40^{T H}$ STREET

SEATTLE, WA 98105 